\title{
Prevalence of Oxyuriasis and its Relationship With Eosinophilia in Children Aged 1 to 6 Years in Marand City, East Azerbaijan Province, Iran
}

\author{
Yagoob Garedaghi ${ }^{* *}$, Behrang Esfandiyari ${ }^{2}$, Hamidreza Hassanzadeh Khanmiri ${ }^{3}$ \\ ${ }^{1}$ Department of Parasitology, Tabriz Branch, Islamic Azad University, Tabriz, Iran \\ ${ }^{2}$ Postgraduate Student of Veterinary Medicine (D.V.M), Tabriz Branch, Islamic Azad University, Tabriz, Iran \\ ${ }^{3}$ Department of Basic Sciences, Maragheh branch, Islamic Azad University, Maragheh, Iran
}

\begin{abstract}
Introduction: Enterobius vermicularis, commonly known as pinworm, is one of the most prevalent intestinal nematodes of humankind belonging to the Oxyuridae family. It is a small, white or transparent, threadlike roundworm. The length of the male worm is 2 to $3 \mathrm{~mm}$ and the female worm is 3 to $8 \mathrm{~mm}$ in length. This study was performed to determine the prevalence of $E$. vermicularis and its relationship with disease symptoms, allergic disease symptoms, and eosinophilia in children aged one to six years in Marand city of East Azerbaijan province, Iran.

Methods: In this descriptive-analytical study, 200 children were studied using systematic random sampling. Data collection method was based on a questionnaire, peripheral blood smear, and Scotch tape test. In the designed questionnaire, children's characteristics such as gender and age and parents' characteristics including job and level of education were recorded. Peripheral blood smear slides were obtained from each child and examined for eosinophilia by a hematologist. Scotch test samples were prepared by parents after providing the necessary training on its sampling method and then examined in the laboratory for the presence of $E$. vermicularis eggs by a parasitologist.

Results: In this study, 64 (32\%) children were diagnosed with oxyuriasis. The prevalence of oxyuriasis was $36.5 \%$ in boys and $43.7 \%$ in girls. There was no significant relationship between oxyuriasis and its symptoms. Additionally, there was no significant relationship between oxyuriasis and allergic disease symptoms. Fourteen children had eosinophilia (7\%), of which $9(64 \%)$ were infected with $E$. vermicularis. There was a significant relationship between $E$. vermicularis infection and eosinophilia $(P<0.05)$. Conclusion: According to the results of the study and the importance of the issue for the control and prevention of this disease, it is suggested that people should be provided with the necessary information about the life cycle, ways of transmission, and especially ways to prevent $E$. vermicularis infestation, and basic measures should be taken to improve the economic situation of the people of the region and to promote public and personal health through public education. Finally, medical treatment of patients and their families should be considered at the same time.

Keywords: Oxyuriasis, Eosinophilia, Children, Marand city, Iran
\end{abstract}

Received: June 6, 2020, Accepted: August 19, 2020, ePublished: October 14, 2020

\section{Introduction}

Enterobius vermicularis, commonly known as pinworm, is one of the most prevalent intestinal nematodes of humankind belonging to the Oxyuridae family. It is a small, white or transparent, threadlike roundworm. The length of the male worm is 2 to $3 \mathrm{~mm}$ and the female worm is 3 to $8 \mathrm{~mm}$ in length. And in their head areas, these pinworms have a pair of alea $(1,2)$. Eggs are ovoid and asymmetrically flattened and the outer layer of the eggs is made up of albumin, which easily adheres to clothes and other objects, and once inside the uterus, these pinworms make a home and larvae are formed quickly $(3,4)$. Humans are the only known hosts of the $E$. vermicularis. This worm typically inhabits the cecum and its adjacent parts in the large and small intestines. This worm is one of the most common nematodes, especially at young ages, among different and even advanced societies of the world and it is estimated that more than 200 million people worldwide are affected (5). The infection rate was reported to be $66 \%$ in polar regions, $60 \%$ in Brazil, $21 \%$ in Thailand, $13 \%$ in Washington, and 22\% in Argentina. This Infection has been reported to be $2.38 \%$ in Isfahan, Iran (6-8).

Infection is significantly more common in children. Clinical signs of infection with this worm include anal itching, vulvovaginitis, anorexia, lack of sleep, weight loss, increased irritability, gnashing of teeth, and abdominal pain. There are case reports of this worm found in the eyes, ears, nose, vagina, peritoneum, liver, and lungs. Moreover, the relationship between infection with this worm and allergies in children as well as eosinophilia in patients has been observed $(9,10)$. This parasite is more 
common in the economically disadvantaged groups of mental retardation institutions and orphanages. However, it is not uncommon among the rich, educated, and even upper class families (11). Since the exact prevalence of the parasite in different parts of East Azerbaijan province is not known, it was chosen as the study area. It is one of the most fertile areas of the province, which is somewhat unique in terms of geography and climate, and on the other hand, customs, food habits, and culture of the people of this area is more traditional. The aim of this study was to investigate the prevalence of $E$. vermicularis infection and its relationship with the symptoms of oxyuriasis, allergy, and eosinophilia in children aged 1 to 6 years in Marand city located in northwestern Iran.

\section{Materials and Methods}

In this descriptive-analytical study, 200 children aged 1-6 years old were randomly sampled from 8 neighboring villages located in Marand city, East Azerbaijan province. The data were collected by demographic information questionnaire. Additionally, clinical signs and symptoms were evaluated, which included anal itching over the past few months, a history of insomnia and restlessness sleep, nocturnal pruritus, frequent bedwetting, teeth grinding, overactivity, history of restlessness and crying over the past few months, weight loss by age, a history of decreased appetite over the past few months. Peripheral blood smear was prepared by a lancet from the fingertips of the subjects and immediately after drying, it was fixed with methanol, stained in the Parasitology Laboratory by Giemsa method, and studied by the parasitologist. To do Scotch tape test, parents were trained. Hence they prepared Scotch tapes at home by pressing the adhesive cellulose tape with an abslang to the anal folds of their children three times a day in the early morning before washing. Scotch tapes collected by parasitologists were examined for the presence of parasite eggs.

The collected data were analyzed using descriptive statistics and chi-square test in SPSS.

\section{Results}

In this study, 64 (32\%) children were diagnosed with oxyuriasis. The prevalence of oxyuriasis was $36.5 \%$ in boys and $43.7 \%$ in girls. There was no significant relationship between E. vermicularis infection and its symptoms. According to the results of statistical tests, a significant relationship was observed between the prevalence of worms and age $(P<0.01)$. Additionally, a significant relationship was observed between fathers' educational level and parasitic infection $(P<0.001)$. The lowest prevalence of infection was observed in children whose fathers had a university education (Table 1 ). There was no significant relationship between the prevalence of $E$. vermicularis infection and the educational level of mothers $(P<0.05)$.

Between worm infestation and clinical symptoms including nocturnal anal pruritus, insomnia, enuresis, teeth grinding, decreased appetite, restlessness, hyperactivity, weight loss, nausea and vomiting, abdominal pain, discharge and itching of the female genital area, and history of urinary infection did not show any significant relationship.

There was no significant relationship between $E$. vermicularis infection and symptoms of allergic diseases such as runny nose, wheezing, itchy eyes, and red eyes. Sneezing for more than two weeks was significantly lower in people infected with the worm.

Among 14 patients with eosinophilia, 9 were infected with $E$. vermicularis and a significant relationship was observed between eosinophilia and E. vermicularis infection $(P<0.001)$ (Table 2$)$.

\section{Discussion}

In this study, 200 children aged 1 to 6 years from the villages around Marand city, East Azerbaijan province in Iran, were examined for worm infestation and an overall prevalence of $32 \%$ was found. In a study conducted in schools of Zahedan, a prevalence of $38.1 \%$ was reported. Moreover, a prevalence of $31.3 \%$ in desert and mountainous areas of Kashan and $2.83 \%$ in kindergartens of Isfahan was observed. This rate of prevalence was higher than that in most studies conducted in other

Table 2. Relationship Between Enterobius vermicularis Infection in Children 1 to 6 Years Old and Peripheral Blood Eosinophilia

\begin{tabular}{lcccccc}
\hline \multirow{2}{*}{$\begin{array}{l}\text { Enterobius } \\
\text { vermicularis } \\
\text { Infection }\end{array}$} & \multicolumn{2}{c}{ Have } & \multicolumn{2}{c}{ Does not have } & \multicolumn{2}{c}{ Total } \\
\cline { 2 - 7 } & No. & $\%$ & No. & $\%$ & No. & $\%$ \\
\hline Have & 9 & 64 & 55 & 30 & 64 & 32 \\
Does not have & 5 & 36 & 131 & 70 & 136 & 68 \\
Total & 14 & 100 & 186 & 100 & 200 & 100 \\
\hline
\end{tabular}

Table 1. Relationship Between Enterobius vermicularis Infection in Children Aged 1 to 6 Years and Fathers' Education

\begin{tabular}{|c|c|c|c|c|c|c|c|c|c|c|c|c|}
\hline \multirow{3}{*}{$\begin{array}{l}\text { Enterobius } \\
\text { vermicularis } \\
\text { Infection }\end{array}$} & \multicolumn{12}{|c|}{ Father's Education } \\
\hline & \multicolumn{2}{|c|}{ Illiterate } & \multicolumn{2}{|c|}{ Elementary School } & \multicolumn{2}{|c|}{ Junior High School } & \multicolumn{2}{|c|}{ High School } & \multicolumn{2}{|c|}{ University } & \multicolumn{2}{|c|}{ Total } \\
\hline & No. & $\%$ & No. & $\%$ & No. & $\%$ & No. & $\%$ & No. & $\%$ & No. & $\%$ \\
\hline Have & 20 & 37.8 & 48 & 58.5 & 16 & 44.5 & 9 & 37.5 & 1 & 20 & 64 & 32 \\
\hline Does not have & 33 & 62.2 & 34 & 41.5 & 20 & 55.5 & 15 & 62.5 & 4 & 80 & 136 & 68 \\
\hline Total & 53 & 100 & 82 & 100 & 36 & 100 & 24 & 100 & 5 & 100 & 200 & 100 \\
\hline
\end{tabular}


countries (12-14).

Due to the high prevalence of worms in the study area, it can be stated that the economic situation, the level of public awareness of health issues, education, and health status in the region is lower compared to other parts of the country, which requires special attention of health officials to the people of the region.

The prevalence of $E$. vermicularis infection was determined in different age groups. The highest prevalence belonged to the age group of 5-6 years and the prevalence of worms increased with age. It is likely that the prevalence is higher in primary school children. In most domestic and foreign studies, the prevalence was directly related to age (15). Therefore, the prevalence of oxyuriasis was reported to be high in the age group of 5 to 14 years. The high prevalence in this age group can be attributed to factors such as children's close relationship with each other and independence from parents in terms of personal hygiene and nutrition activities and doing them in an unsanitary and incorrect manner (16). In primary schools of Zahedan city, the highest prevalence belonged to the age of 9 and the lowest belonged to the age of 10. In another study in Malaysia, which reported a prevalence of $12.5 \%$, the correlation between worm infestation and age was the highest, with the highest incidence among children aged 3 to 6 years. Additionally, similarity in the results regarding the age in different parts of the world can probably be due to children's common behavior in dealing with health issues or relatively low understanding of infectious agents and routes of transmission $(17,18)$.

There was a statistically significant relationship between $E$. vermicularis infection and fathers' education. The above-mentioned results show that in rural areas, people with university education are at a higher level in terms of health issues and care for their children. There was no significant relationship between the prevalence of E. vermicularis infection and the educational level of mothers. However, none of the mothers of the studied children had a university education. Among the risk factors mentioned for the prevalence of this infection are the management of kindergartens and primary schools, the level of parental awareness, the condition of the beds, washing hands before eating, cleaning after the toilet, finger sucking, and being members of large families. Among the mentioned risk factors, the level of knowledge of fathers in this study had an effect on the rate of worm infestation. However, transmission through infected hands plays a more prominent role in the life cycle of the parasite (19).

In this study, no significant relationship was observed between worm infestation and clinical symptoms including nocturnal anal pruritus, insomnia, enuresis, teeth grinding, decreased appetite, restlessness, hyperactivity, weight loss, nausea and vomiting, abdominal pain, discharge and itching in the female genital area, and a history of urinary infection.
This is similar to the results obtained in previous studies, indicating that E. vermicularis infection is often asymptomatic and its most common symptoms are nocturnal anal pruritus, irritability, and insomnia. Other symptoms have been reported rarely and occasionally. However, a significant relationship was reported between worm infestation and clinical symptoms such as anal itching, insomnia, and abdominal pain in Argentina (20).

One of the reasons for the lack of a significant relationship between E. vermicularis infection and its symptoms is less parental control over their children, indicating that children in the study area often spend the day outside the home and away from parents. Therefore, the chances of seeing symptoms in children along with their parents are reduced. Other causes include the young age of children who are unable to express some of their complaints, such as insomnia and even anal itching, while most of the subjects studied in Argentina were adults or older children who were easily able to express their problems and symptoms. Another reason for the lack of relationship between $E$. vermicularis infection and clinical symptoms could be that the severity of infection was not measured in infected people in this study and infections were identified as positive or negative based on the detection of a small number of eggs. In the slides, the worm load was probably low in infected individuals, so the mild symptoms observed may be due to the small number of parasites in infected individuals $(21,22)$.

In this study, no significant relationship was observed between E. vermicularis infection and symptoms of allergic disease. However, previous studies have shown different results. In a study conducted in Taipei, an inverse relationship was found between worm infestation and allergic diseases. On the other hand, researchers in a study conducted in Sweden showed that worm infection is common in children with allergic diseases (23). Most previous studies have shown that parasites such as $E$. vermicularis that do not invade tissue do not cause eosinophilia. Given that children were not tested for infection with other parasitic worms in the current study, other factors that cause eosinophilia in these children should be checked. However, it should be noted that the immune system response to E. vermicularis is related to type $2 \mathrm{~T}$ cells, which manifests itself as an increase in eosinophils, and it should be expected that infected individuals have more eosinophils compared to noninfected people (24).

In this study, out of the total number of people diagnosed with worms, 24 were positive in the first slide test, 32 in the second slide test, and 12 in the third slide test (which was not necessarily positive in previous tests) for parasite eggs.

As it turns out, if only one sample of Scotch tape test was prepared from these children for testing, a much lower prevalence rate would be obtained. In this study, probably one of the reasons for the higher prevalence rate 
compared to other domestic studies is performing three Scotch tests. This result indicates the need for three tests to accurately determine the infection of individuals.

\section{Conclusion}

Although E. vermicularis infestation is referred to as a common, benign, and generally "asymptomatic and tolerable" infection in most sources, there are several reports about symptoms and even complications. In the present study, considering the above-mentioned prevalence rates, most of the symptoms studied in patients with oxyuriasis, except for sneezing and eosinophilia, were observed.

\section{Conflict of Interests}

The authors declare that they have no conflict of interests.

\section{Ethical Issues}

In this research, ethical considerations have been fully observed.

\section{Acknowledgements}

The authors would like to express our deep gratitude to Islamic Azad University, Tabriz Branch, for offering valuable theoretical and practical contributions to the research team in the present study.

\section{Authors' Contributions}

YG did the writing and editing of the manuscript. BE did data collection and $\mathrm{HHKH}$ did statistical analysis.

\section{Funding}

The authors received no financial support for the research, authorship, and publication of this article

\section{References}

1. Gunawardena NK, Chandrasena TN, de Silva NR. Prevalence of enterobiasis among primary school children in Ragama, Sri Lanka. Ceylon Med J. 2013;58(3):106-110. doi:10.4038/cmj.v58i3.5039

2. An YW, Pang XL, Liu JB, et al. [Survey of distribution of Enterobius vermicularis infection of children in Huadu District, Guangzhou city]. Zhongguo Xue Xi Chong Bing Fang Zhi Za Zhi. 2013;25(6):636-638.

3. Chen YD, Wang JJ, Zhu $\mathrm{HH}$, et al. [Enterobius vermicularis infection status among children in 9 provinces/autonomous regions/municipalities of China]. Zhongguo Ji Sheng Chong Xue Yu Ji Sheng Chong Bing Za Zhi. 2013;31(4):251-255.

4. Wu CG, Xie J, Luo X], et al. [Influence factors of Enterobius vermicularis infection among pupils in Chongqing city]. Zhongguo Ji Sheng Chong Xue Yu Ji Sheng Chong Bing Za Zhi. 2012;30(5):382-386.

5. Jiang CG, Li SM. [Investigation of pinworm infection among kindergarten children in Jurong city, Jiangsu province]. Zhongguo Ji Sheng Chong Xue Yu Ji Sheng Chong Bing Za Zhi. 2013;31(5):355-356.

6. Ng YW, Ng SB, Low JJ. Enterobius vermicularis infestation of the endometrium - a cause of menstrual irregularity and review of literature. Ann Acad Med Singap. 2011:40(11):514-515.
7. Serpytis M, Seinin D. Fatal case of ectopic enterobiasis: Enterobius vermicularis in the kidneys. Scand / Urol Nephrol. 2012;46(1):7072. doi:10.3109/00365599.2011.609834

8. Pampiglione S, Rivasi F. Enterobiasis in ectopic locations mimicking tumor-like lesions. Int J Microbiol. 2009;2009:642481. doi:10.1155/2009/642481

9. Gunawardena NK, Chandrasena TN, de Silva NR. Prevalence of enterobiasis among primary school children in Ragama, Sri Lanka. Ceylon Med J. 2013;58(3):106-110. doi:10.4038/cmj.v58i3.5039

10. Bøås H, Tapia G, Sødahl JA, Rasmussen T, Rønningen KS. Enterobius vermicularis and risk factors in healthy Norwegian children. Pediatr Infect Dis J. 2012;31(9):927-930. doi:10.1097/ INF.0b013e318258cdb5

11. Afrakhteh N, Marhaba Z, Mahdavi SA, et al. Prevalence of Enterobius vermicularis amongst kindergartens and preschool children in Mazandaran province, North of Iran. J Parasit Dis. 2016;40(4):1332-1336. doi:10.1007/s12639-015-0683-z

12. Sayyari AA, Imanzadeh F, Bagheri Yazdi SA, Karami H, Yaghoobi M. Prevalence of intestinal parasitic infections in the Islamic Republic of Iran. East Mediterr Health J. 2005;11(3):377-383.

13. Sharifi B, Kh A. Determination of oxiur prevalence in Zahedan schools 2000. Tabibe Shargh Med J. 2000;5(5):25-28.

14. Rasti S, Arbabi M, Hooshyar H. High prevalence of Entamoeba histolytica and Enterobius vermicularis among elderly and mentally retarded residence in Golabchi center, Kashan, Iran 2006-2007. Jundishapur J Microbiol. 2012;5(4):585-589. doi:10.5812/jjm.4576

15. Herrström $P$, Henricson KA, Råberg A, Karlsson A, Högstedt B. Allergic disease and the infestation of Enterobius vermicularis in Swedish children 4-10 years of age. I Investig Allergol Clin Immunol. 2001;11(3):157-160.

16. Anuar TS, Jalilah L, Norhayati M, Azlin MY, Fatmah MS, Al-Mekhlafi HM. New insights of Enterobius vermicularis infection among preschool children in an urban area in Malaysia. Helminthologia. 2016;53(1):76-80. doi:10.1515/helmin-2015-0077

17. Kuang $\mathrm{CP}, \mathrm{Wu} \mathrm{XL}$, Chen WS, Wu FF, Zhuo F. [Prevalence and risk factors of Enterobius vermicularis among preschool children in kindergartens in Luohu District, Shenzhen city]. Zhongguo Xue Xi Chong Bing Fang Zhi Za Zhi. 2015;27(1):76-78.

18. Cranston I, Potgieter N, Mathebula S, Ensink JH. Transmission of Enterobius vermicularis eggs through hands of school children in rural South Africa. Acta Trop. 2015;150:94-96. doi:10.1016/j. actatropica.2015.07.001

19. Pezzani BC, Minvielle MC, de Luca MM, Cordoba MA, Apezteguia MC, Basualdo JA. Enterobius vermicularis infection among population of General Mansilla, Argentina. World I Gastroenterol. 2004;10(17):2535-2539. doi:10.3748/wjg.v10.i17.2535

20. Garedaghi Y. Seroprevalence of toxocariasis in children in EastAzerbaijan province, Iran. Cukurova Med J. 2013;38(4):581-586.

21. Chang TK, Liao CW, Huang YC, et al. Prevalence of Enterobius vermicularis Infection among preschool children in kindergartens of Taipei city, Taiwan in 2008. Korean / Parasitol. 2009;47(2):185187. doi:10.3347/kjp.2009.47.2.185

22. Herrström P, Friström A, Karlsson A, Högstedt B. Enterobius vermicularis and finger sucking in young Swedish children. Scand J Prim Health Care. 1997;15(3):146-148. doi:10.3109/02813439709018505

23. Galioto AM, Hess JA, Nolan TJ, Schad GA, Lee JJ, Abraham D. Role of eosinophils and neutrophils in innate and adaptive protective immunity to larval Strongyloides stercoralis in mice. Infect Immun. 2006;74(10):5730-5738. doi:10.1128/iai.01958-05

24. Saravi KH, Fakhar M, Nematian J, Ghasemi M. Co-infection with Enterobius vermicularis and Taenia saginata mimicking acute appendicitis. J Infect Public Health. 2016;9(4):519-522. doi:10.1016/j.jiph.2015.11.013

C 2020 The Author(s); This is an open-access article distributed under the terms of the Creative Commons Attribution License (http:// creativecommons.org/licenses/by/4.0), which permits unrestricted use, distribution, and reproduction in any medium, provided the original work is properly cited. 